\title{
Optimization Design for Sulfur Dioxide Flow Monitoring Apparatus in Thermal Power Plants
}

\author{
Hao-wei Hu ${ }^{1, a}$, Xue Yang ${ }^{1, b}$ and Xiao-wei Song ${ }^{1, c}$ \\ ${ }^{1}$ School of energy power and mechanical engineering, \\ North China Electric Power University, Baoding 071003,China. \\ afarstreet@163.com, ${ }^{\mathrm{b}} 1587118906 @ q q . c o m,{ }^{c} 1696401843 @ q q . c o m$
}

Keywords: $\mathrm{SO}_{3}$; manual controlled condensation method; flow monitoring apparatus; optimization design.

\begin{abstract}
The flue gas flow from thermal power plant is an important standard in the environmental monitoring process to judge whether the procedure need improving. Because of the low flow of $\mathrm{SO}_{3}$ and its profound impact on the environment, it is hard but necessary to monitor the precise content at present overall. Combined with current situations in the thermal power plant, this paper first gives some introduction to the traditional measurements methods for $\mathrm{SO}_{3}$, especially the manual controlled condensation method. Then optimize the existing problems in the process of monitory, designing a simple $\mathrm{SO}_{3}$-monitoring apparatus which can be arranged near a flue in the sub period, to realize optimization for the original technology with high precision flowmeter and new materials.
\end{abstract}

\section{Introduction}

With the continuous development of society, human demand for energy is increasing. Occupying the dominated position in recent years, China's primary energy consumption of coal has been kept at over $70 \%$, and this coal-based energy consumption structure will not change in a short time. So a lot of burning coal will produce a variety of pollutants such as $\mathrm{SO}_{\mathrm{x}}$ and $\mathrm{NO}_{\mathrm{x}}$, which may cause serious and unpredictable environmental problems.

When combusted, the sulfur in coal is initially oxidized to $\mathrm{SO}_{2}$, but during which a small percentage of the $\mathrm{SO}_{2}$ (about 0.5 to $1.5 \%$ in the boiler) will continue to be oxidized to $\mathrm{SO}_{3}$. At present, in order to control nitrogen oxide emissions, denitrification mainly uses selective catalytic reduction (SCR) technology, but existing commercial catalysts will lead to the conversion of $\mathrm{SO}_{2}$ to $\mathrm{SO}_{3}$, increasing the generation and emissions of $\mathrm{SO}_{3}$ (including $\mathrm{H}_{2} \mathrm{SO}_{4}$ ) , and causing serious problems [1], such as corrosion of downstream equipment, fouling of the air pre-heater and SCR catalyst, reduction of the denitration activity and damage to the environment and human health.

In summary, the concentration on the flue gas monitoring and boiler operating conditions has become a necessary means in inspection and evaluation of the SCR catalyst. But the difficulties to accurately detect $\mathrm{SO}_{3}$ and $\mathrm{H}_{2} \mathrm{SO}_{4}$ lie in[2]:

(1) The composition in boiler flue gas is complex, which exerts interference in detection of $\mathrm{SO}_{3}$ and $\mathrm{H}_{2} \mathrm{SO}_{4}$. What's more, high-temperature flue gas conditions make ordinary sampling techniques difficult to ensure the accuracy.

(2) $\mathrm{SO}_{3}$ is chemically active and $\mathrm{H}_{2} \mathrm{SO}_{4}$ aerosol absorption is strong, both of which can easily be wall adsorption by various substances, and make measuring instruments and sampling equipment broken down by corrosion.

(3) Flue gas always contains $\mathrm{SO}_{2}$ with high concentration, which is easily oxidized absorbent to generate $\mathrm{H}_{2} \mathrm{SO}_{3}$, so that the measurement result is high.

(4) Fly ash particles in the flue gas is apt to condense, and easy to plug the sample pipe, causing difficulties for accurate sampling. And the concentration of $\mathrm{SO}_{3}$ in flue gas is low, and a smaller measurement error will bring a large relative error. 


\section{Technical Support}

In order to accurately measure $\mathrm{SO}_{2}$, a variety of detection methods have been proposed, but there is still no uniform technology widely recognized. Among them, manual controlled condensation method is the most accurate one. Its principle is: remove flue gas using a heated sampling gun, and then drive it into the heating apparatus, in this process sampling gun's temperature should be above 260 degrees (if the temperature is too low, acid steam are easily formed by condensation in the pipeline, thus affecting the temperature of measurement), so the temperature of probe can be heated above the dew point of sulfuric acid. Since the ash in flue gas will react or condense with the sulfuric acid vapor, the probe must install a filter device to remove smoke particles. On the other hand, heating temperature should not be too high, because the flue gas contains fly ash as catalysis, if the temperature is too high, the filtering may easily convert $\mathrm{SO}_{2}$ into $\mathrm{SO}_{3}$, resulting in the measurement error. After passing through the filter to reach the condenser, the temperature of condenser is generally between 65 to 110 degrees, where sulfuric acid and $\mathrm{SO}_{3}$ is condensed, and the serpentine tube, by using centrifugal force, can adsorb mist thereby collect $\mathrm{SO}_{3}$ and $\mathrm{H}_{2} \mathrm{SO}_{4}$.

\section{Apparatus Design}

Utilizing the principle of manual controlled condensation, now we can design a device to simply measure $\mathrm{SO}_{3}$. Under the background of the practical application of thermal power plants, flue gas flow is generally little change in different sectors and always flows at the speed of about $10 \mathrm{~m} / \mathrm{s}$, depending on the load on the boiler. Temperature near boiler chimney is generally between 130 and 150 degrees, near the economizer outlet is at 300 to 400 degrees, and in the import of cold air pre-heater is about 30 degrees. To ensure the temperature of $\mathrm{SO}_{3}$ in the flue gas is not lower than the acid dew point, and is not so high that could damage the device, we intend to install it in the boiler chimney outlet, i.e. in the area where flue gas's temperature is between 130 and 150 degrees. In this position, smoke can quickly reach the set temperature, reduce the loss, also to ensure that no damage to the instrument, expanding its life.

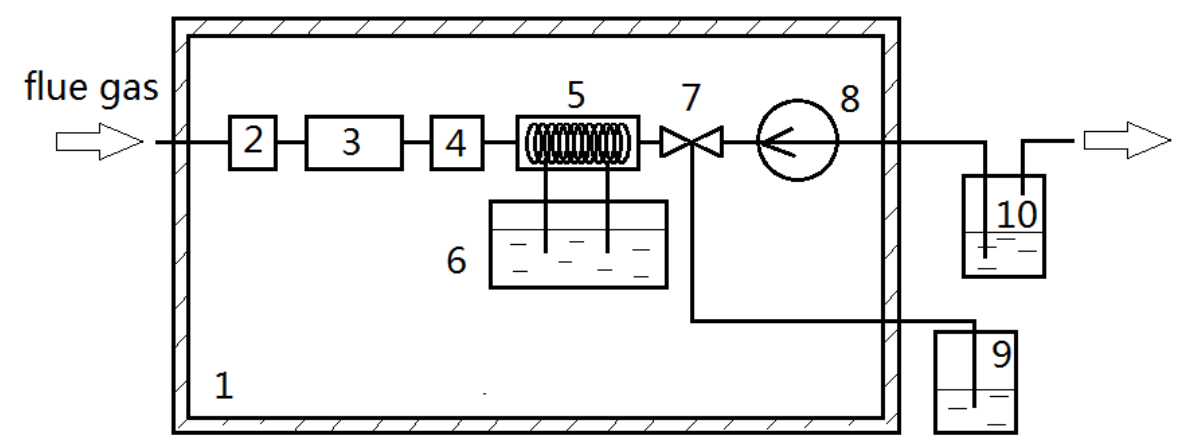

1.fixed apparatus; 2.flowmeter; 3.sample-heating device; 4.filter;

5.condenser; 6.circulating water; 7.gas-liquid separator; 8.vacuum pump;

9.volumetric soiution; 10. exhaust gas treatment apparatus

Figure. 1 The design of the apparatus

Taking into account the technical shortcomings in traditional controlled condensation, now we set to improve the measurement system, as is shown in Figure 1. The size of the apparatus is designed to $1 \mathrm{~m} \times 0.5 \mathrm{~m} \times 0.5 \mathrm{~m}$, placed on the chimneys outlet, and long-term work in the environment of approximately 200 degrees. Flue gas sequentially through the flowmeter, the heating apparatus, the filter and the condenser to obtain $\mathrm{SO}_{3}$. When its content needs to be titrated, the $\mathrm{SO}_{3}$ can be withdrawn by a vacuum pump through the gas-liquid separator, then the remaining gas will be disposed through the exhaust gas treatment apparatus to the atmosphere. Flowmeter is used for monitoring whether the gas flow is stable, the heating device is used to ensure the temperature is above the acid dew point, and the filter for the adsorption of fly ash in the flue gas.

Our measuring system focuses on the following aspects:

(1) The addition of high-precision flowmeter to realize real-time and continuous measurement. 
(2) Design a more efficient rapid heating apparatus to preheat the flue gas.

(3) Improve filtering effect and more efficient selection of filtering filler.

(4) Design fixed apparatus, use new corrosion-resistant material that can be placed directly to the flue-gas exports in the thermal power plants and reduce the loss of $\mathrm{SO}_{3}$ during transportation.

\section{Technical Line}

\section{Flow Monitoring [3]}

In the link of power plant desulfurization, flue gas emission is a continuous and fluctuate process, which means the monitoring value of flow is very unstable, and jumps greatly. In order that the content of $\mathrm{SO}_{3}$ can be obtained per time accurately, only when the flow is relatively stable can we sample the flue gas. So before the determination of the components, first we shall measure the total flow.

In the application background of thermal power plant, there are certain requirements on the measurement of flow rate, mainly reflected in two aspects as follows:

(1) As the flue gas temperature near chimney outlet is high, the flowmeter should have a high temperature resistant capability to ensure the long-term field monitoring online.

(2) High sensitivity. Due to the emission of flue gas has a high environmental protection requirements, and the power plant operation must ensure the safety and stability, so the meter must have high sensitivity to smoke so as to ensure the accuracy in monitoring $\mathrm{SO}_{3}$.

Based on these points to consider, thermal mass flow detection technology is the best choice of flow monitoring. Thermal mass flow detection technology is a kind of flow detection technology based on the thermodynamics. The basic principle is the cooling effect when the gas flows through the heating element, which is mainly used in boiler, petrochemical, flare gas mass flow measurement, combustion furnace for mass flow control measurement of air and so on.

Here is a selection of resistance probe meter, as is shown in Figure 2.

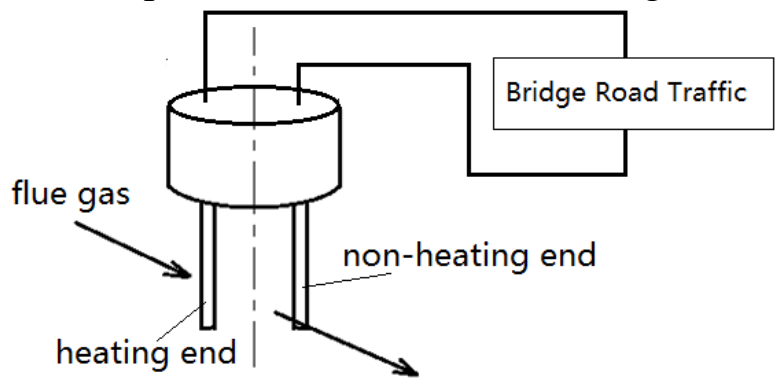

Figure. 2 Resistance probe meter

Resistance probe flowmeter works by two platinum resistance side by side as probes, divided into a heating end and a non-heating end. Non-heating end is used to measure the fluid environment temperature while heating end is heated by an independent heater. When the fluid velocity in the flow field is zero, it can be considered that the probes are without heat loss, at which time the two platinum resistance have the maximum temperature difference; when the fluid velocity is increasing, heat in the heated one can be taken away, reducing the temperature difference between, which can be detected by external Bridge Road Traffic. Here the heating end remains a constant heating temperature higher than the environment's, which can be realized through the feedback circuit, and then through the current or voltage detecting changes to measure fluid flow.

The flowmeter has a long-term work at 40 to 300 degrees and 1.6 to $10 \mathrm{MPa}$, but more than 200 degree it needs to add a heat sink. Its measuring accuracy is from $\pm 0.5 \%$ to $\pm 2.5 \%$, a high accuracy. And because of its small thermal hysteresis effect, dynamic response width of small pressure loss, large dynamic range, it is almost not affected by fluid density, pressure, temperature, viscosity and other parameters, so it is suitable for the actual placement of environmental requirements. 


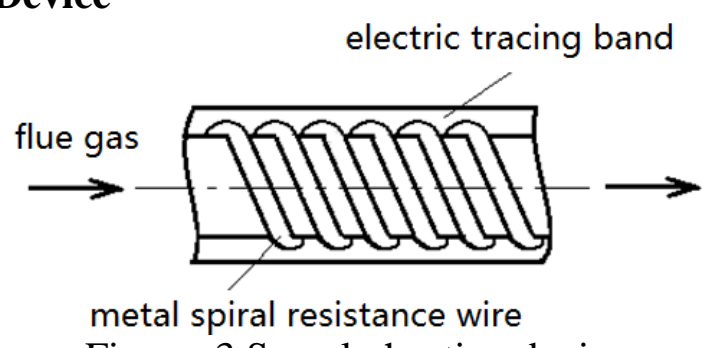

Figure. 3 Sample-heating device

As is mentioned earlier, $\mathrm{SO}_{3}$ is subject to absorb moisture, and then converted into sulfuric acid steam. Because $\mathrm{H}_{2} \mathrm{SO}_{4}$ is easy to condense and corrode measuring device, which will cause a large deviation, therefore a heating device must be installed in front to make the sulfuric acid dew point temperature reached in a very short period of time, i.e. 140 to 160 degrees. In view of the above analysis, this paper uses the improved heating device to heat flue gas.

Flue gas is heated by an electric heating tube, made of metal spiral resistance and the crystallization of magnesium oxide. Because the tube uniformly distributed high temperature resistance wire, the gap part is filled with well heat-conducting properties and has good insulation performances, so the thermal efficiency of the device is high, and the heating is uniform.

While heated, temperature control device is also arranged outside the electric tracing band in order to improve the heating efficiency. It can with the temperature change of the heating system automatically adjust the output power and change heating temperature, therefore not be burnt.

Because the device conducts heating and insulation links in parallel, it can effectively ensure that the flue gas in a short time is rapidly heated to above acid dew point, and then continue to maintain a relatively stable temperature.

\section{Improvement of Porous Glass Fiber Filter}

With the development of technology, the chemical industry urges a higher quality and reliability of operating environment, which brings more serious requirements on filter performance. According to the actual operating situation, the selection of filters must ensure its high temperature is above 200 degrees and can not react with acidic material. For pooling more advantages and eliminating outside interference to achieve accurate measurement of $\mathrm{SO}_{3}$, this paper combines PTFE fiber and glass fiber to improve the filter.

Combining PTFE fiber and glass fiber can reach high strength, good stability, easy ash-cleaning and corrosion resistance, and two of them belong to the high temperature resistant material, realizing the complementary advantages. The glass fiber can work at a temperature of 260 degrees(alkali) or $280 \mathrm{C}$ (alkali free) for a long term, and PTFE can work continuously at 280 degrees, whose melting point is 327 degrees. The combination of the two ensures the filtering precision to reach $0.01 \mu \mathrm{m}$, therefore the filtration effect of fly ash is better, and keeps stable in the high temperature.

\section{The Choose of Corrosion-resistance Material}

In the application of $\mathrm{SO}_{3}$ measurement, the apparatus is relatively small (total surface area is about $2.5 \mathrm{~m}^{2}$ ), so we choose Bingaud glass brick as a corrosion-resistance material to protect the whole apparatus (a fixed apparatus), which can long-term work under the temperature of 180 degrees and effectively anti-corroded, so for the system safety and durability is a big upgrade.

The advantages of Bingaud glass brick anti-corrosion system are: good corrosion resistance, corrosion resistant to various acid and alkaline solution; the excellent thermal shock resistance capability, high temperature resistance to 516 degrees; light weight and less additional load to the structure.

\section{Summary}

Based on manual controlled condensation method, we analyze the content of $\mathrm{SO}_{3}$ in the flue gas, and the key technology of its measurement accuracy are extracted, which launched a series of research improvement: 
(1) Increasing the thermal flowmeter in front of the original device and using stable data to analyze flue gas on the given time, to reduce the error caused by the instability of flue gas flow;

(2) Adopt metal spiral resistance wire, the crystallization of magnesium oxide and other components in the electric heating pipe, and the improved heating device to heat gas, improving the efficiency and reducing the sulfuric acid droplets generated, thereby improving the accuracy of measurement;

(3) Filter is combined PTFE fiber with glass fiber, reducing interference and improving the high temperature resistance and corrosion resistance;

(4) The fixed apparatus is added so that the whole device can be fixed on the flue gas outlet, and reduces the loss of $\mathrm{SO}_{3}$ in the process of conveying.

\section{Reference}

[1] Zhang You. Research and application of SO3 measurement in flue gas. (2013)

[2] Xiao Yu-ting, Ja Man, Xu Li,et al. The analytic method of sulfur trioxide and sulfuric acid mist in flue gas,10( 2012) 43-48.

[3] Xie Zhi-zhu. Research on MEMS-based thermal flow measuring method and system. (2007)

[4] Mixed Spin Filter Materials of Polytetrafluoroethlene Fibre and Spun Glass, 2013, pp. 66.

[5] Wang An-ling. Study on coal-fired power plant wet chimney corrosion and abrasion resistant coating, 2014, pp. 21-25. 